\title{
Creating Communicative Space and Textual Reality via Emotiogenic Means in Fictional Discourse
}

\author{
Andrii Bezrukov ${ }^{1} \&$ Oksana Bohovyk ${ }^{2}$ \\ ${ }^{1}$ Ph.D., Assistant Professor, Philology and Translation Dept., Dnipro National University of \\ Railway Transport named after Academician V. Lazarian, Ukraine. \\ ORCID: oooo-ooo1-5084-6969. Email: dronnyy@gmail.com \\ ${ }^{2}$ Ph.D., Senior Lecturer, Philology and Translation Dept., Dnipro National University of \\ Railway Transport named after Academician V. Lazarian, Ukraine. \\ ORCID: oooo-ooo3-4315-2154.Email: oksana.a.bogovik@gmail.com
}

\begin{abstract}
The article focuses on the strategies of reconstructing communicative space between the author and reader as well as forecasting the emotional impact on the reader through transforming textual reality. The emotiogenic characteristics of fictional discourse provide the emotional perception of literary texts since emotions are central to the experience of literary narrative fiction. Such a perception is made possible by the identification, comprehension, and interpretation of the emotionally significant textual components of different types. The authors of the article have classified them as the following: graphical and visual, punctuation, and semantic-stylistic ones. These means, found in the postmodern novels by Salman Rushdie, Tahereh Mafi, Marina Lewycka, Kazuo Ishiguro, Alexandar Hemon, and Stephen King, have been analysed to explicate the character of the phenomenon of emotiogenic fictional narratives. The emotiogenic means in the selected novels are exploited by the writers of different ethnic affiliations that can be resulted from their multicultural experience. The superimposition of some means is explained by their semantic relationship. The article tests a hypothesis that the cognitive architecture of the emotiogenic means is determined by an emotional situation reflected in a literary text that appears to be a special code through which readers interpret their emotional and evaluative meanings. The indicators of the text's emotionality occur to be signs of the textual representation of emotional knowledge. This study contributes to the investigation of the emotiogenic means of creating communicative space which are considered those discursive expressive elements that affect the perception of textual reality.
\end{abstract}

Keywords: emotion, text, author, reader, postmodern literature, cognition

\section{Introduction}

The narratives that determine communicative intentions in cultures may differ, and this suggests that the emotional response can be different either. These narratives are produced and forwarded through culture codes which are defined as "those symbols and systems of meaning that have a specific relevance to members of a particular group or society" (Hyatt \& Simons, 1999, p. 24). In the multicultural dimension, the composition of discourse includes the complex system of using codes. They become embedded through cultural programming. Hofstede et al. (2010) suppose culture to be "collective programming of the mind which distinguishes the members of one group or category

(C) AesthetixMS 2021. This Open Access article is published under a Creative Commons Attribution Non-Commercial 4.0 International License (http://creativecommons.org/licenses/by-nc/4.o/), which permits non-commercial re-use, distribution, and reproduction in any medium, provided the original work is properly cited. For citation use the DOI. For commercial re-use, please contact editor@rupkatha.com. 
of people from another" (p. 6) where they are socialised under a certain system of values and form the key elements of culture. Since emotions are universal phenomena, albeit affected by culture, they promote creating universal imagery. Cultural discourse focuses on distinctive means of communication used in specific contexts and meanings (Carbaugh, 2007). At the same time, the authors of the article are of the opinion that the aforementioned restraints do not work with the emotiogenic means, which create an emotional background of textual space.

The relevance of emotion may be clearly seen in texts of different genres. Since fictional discourse is an objective recording of literary communication and interaction of the author and reader with linguistic socio-interactional and cultural canons (Predelli, 2020; Stamou, 2018; Phillips, 2000), understanding the means of influence, that appear in literary texts as a projection into the emotional perception of what is read, is considered a relevant issue of modern humanities. The projection of meaning into the process of cognition of an emotionally-perceived literary text actualises those emotionally-evaluative layers which are the elements of a conceptual worldview. Personal socio- and linguo-cultural experience produces knowledge about the scripts of emotional situations and stereotypes, which are activated in the reader's mind and represented during the perception and interpretation of an emotional literary text, since "intermental thought is a crucially important component of fictional narrative” (Palmer, 2010, p. 41).

Reading books is imperative in the way it affects the readers' emotional sphere and is referred to as the experience of fictional narratives (Brock et al., 2002; Oatley, 1999). Personal meaning, which reflects the bias of the reader's consciousness in relation to the emotional content of a literary text, generates an emotional indication, i.e. a reflection of the emotional and evaluative characteristics of an image. It may provide people with distraction from mundanity and initiate intellectual inspiration (Oatley, 2002). Inspired by the author's consciousness and reader's experience, the image takes the characteristics of emotions explicated in the artistic dimension. It is an experience in which the element of feeling, as well as the element of emotional coexperiencing of psychological occurrences along with portrayed characters, plays an essential role (Ingarden et al., 1980, p. 273).

The reader being an object of influence and literary communication party modifies a text on the basis of his/her social concepts and stereotypes, and similar concepts and stereotypes that have to be reconsidered, interpreted and evaluated in a text, - an interaction that occurs in the process of actualizing a literary text (Song, 2019; Meskin, 2003; Kneepken \& Zwaan, 1995). Palmer (2004) stresses that "the constructions of the minds of fictional characters by narrators and readers are central to our understanding of how novels work because, in essence, narrative is the description of fictional mental functioning" (p. 12).

The emotiogenic means in a literary text significantly modify this functioning. As Mar et al. (2011, p. 818) claim, emotions are central to the experience of literary narrative fiction. Authors consciously connect the narratives with the emotional and evaluative basis which create the attitude of the author and reader to the textual reality (Harker, 1988). Creators of a literary text evaluate their own experience during the verbalization of an idea as pleasant or unpleasant and an emotional situation as positive or negative for themselves and for the characters since authors are observers of themselves and the world represented in a literary text (Maass, 2016). Evaluating created literary space, authors correlate it with objective reality which appears to be a subjective internal universe model developed in their mind. It tends to be dynamically changeable that associated with an artistic model of the world expressed in a literary text. Describing this or that emotional situation, authors consciously modify the emotional response of readers using their own perception of reality, thus expanding the cognitive and cultural field. 
Fiction has been chosen by the authors of the article as it may elicit stronger emotional and behavioural effects than non-fiction reading (Goldstein, 2009). Six novels were selected to be representatives of different genres in order to demonstrate the multifarious emotiogenic means and the authors' approaches to creating communicative space. They are the allegorical novel The Golden House (2017) by a British-Indian novelist and essayist Salman Rushdie; the dystopian thriller Shatter Me (2011) by an Iranian-American author Tahereh Mafi; the humorous novel $A$ Short History of Tractors in Ukrainian (2005) by a Ukrainian-born British novelist Marina Lewycka; the dystopian science fiction novel Never Let Me Go (2005) by a British novelist and short-story writer of Japanese origin Kazuo Ishiguro; the historical novel The Lazarus Project (2008) by a Bosnian-American fiction writer and journalist Alexandar Hemon; and a science fiction-horror thriller novel The Institute (2019) by an American author Stephen King. The analysis of the above novels through the conception of fictional characters (Thomasson, 2003) allows for paying extra attention to the author's emotional profile through its relation to the characters' emotions and displaying them in literary practices.

Fiction usually involves believability. A fictional text is mostly assessed by the establishment of its verisimilitude, or truthlikeness (Bruner, 2009; Gerrig, 1994). Readers are influenced by creating a narrative world that looks real within the context. It is obvious that the mentioned world is getting more and more important when it becomes realistic for readers. It creates a special emotional background that helps them be drawn into the storyline. Manifestly, non-fictional logico-scientific thinking is not being able to elicit those feelings and emotions (Bruner, 2009; Miall \& Kuiken, 2002). There are characters and events which help readers be changed through fictional narratives and hence change their emotional attitude to textual reality (Bal et al., 2011; Zwaan, 2004).

The main points making the novels suitable for the present study include the different culture codes, individual author's styles, and discourse structure of these pieces of postmodern literature. The selected books, written by the authors of different ethnic affiliations, show the choice and usage of the emotiogenic means which create communicative space in a literary text. Researchers claim that multicultural experience influences creativity (Aytug et al, 2019; Cheng et al., 2011; Leung et al., 2010), especially in using expressive means for creating an emotiogenic system of a text.

This study is undertaken to explicate and analyse the strategies of using the emotiogenic means for creating communicative space and textual reality by contemporary fiction writers. Considering the concepts of emotions in different dimensions (Glynn, 2014; Oster, 2010; Kövecses, 2004) has become more important in the research of the emotiogenic means as a crucial tool for fictionalizing textual reality. To appreciate the chosen approaches, the following methodology that has been used to investigate this relevant topic must be addressed.

\section{Methodology}

We accept the view defining a dialogue in literary communication as a collision of the author's and reader's worldviews since understanding a literary text is determined by socio-psychological and cultural-linguistic forces. An important condition for dialogic interaction in literary communication is the reader's ability to interpret the meaning of a text created by the writer. This ability is determined not only by life experience, value orientations, and culture codes of the addressee but also his emotional competence, which causes emotional reactions during interpreting a text. In our opinion, these reactions are the principal determinant of successful 
literary communication. Literary experience is a high emotion level of art reception that turns a work of art into a fact of the readers' consciousness creating communicative space.

Since the term communicative space has a pronounced interdisciplinary character (Hatavara et al., 2018), it can be interpreted ambiguously and considered a specific space where the content directly depends on a field of study. In the article, communicative space appears to be a literary text as a special form of a dialogue between the author and reader. Such space cannot be clearly structured due to its indefiniteness and dynamism, but it can be created taking into account the author's experience of emotion and its projection on the reader which sometimes affects the stereotypical thinking of both. This raises the problem of fictionality that is an exterior description associated with a text (Cyzman, 2015, p. 72).

The linguo-cognitive component of this space allows us to analyse a literary text in terms of the semantics of the text - mental representation of reality with the involvement of elements of emotions. Readers perceive a text as the main source of their knowledge objectified in it. Emotional breadth and emotional depth of a literary text (fictionalizing discourse) correlate with emotional knowledge which is actualised through the following textual components of emotions: nontraditional graphical and visual images, use or elimination of punctuation marks, and linguistic units including an evaluative component, emotional modality, and semantics. The first and second ones concern textual elements that become emotionally significant due to their visual or semantic representation. The third one means that the emotional significance of emotiogenic signs is usual. It is determined by the characteristics that are inherent in them constantly as semantically accentuated linguistic units.

In this way, the author embodies emotional intentions, affects the reader's emotions, and creates communicative space that is associated with the interpretation of textual reality. As Danes (2004) asserts, "cognition evokes emotion (it is 'emotiogenic'), and emotion affects cognition" (p. 25). Emotional knowledge causes a range of the reader's emotions and is understood as a trinity: knowledge of language / knowledge in language - the activation of the reader's emotional reactions to certain textual elements; knowledge of the world - the interpretation of an emotional response to textual reality; textual knowledge - the definition of the reader's emotional experiences in getting knowledge of textual reality.

An emotional situation reflected in a literary text determines the cognitive architecture of the author's emotiogenic means. This situation appears to be a special code through which readers interpret their emotional and evaluative meanings. To test this hypothesis, the insight of linguostylistics, cultural studies, and psychology is combined with the study of English-language fictional discourse in order to highlight an interdisciplinary approach to postmodern literature.

\section{Graphical Perception: Visual Decoding of Emotional Intensity}

Such emotiogenic graphical means as italic, oblique, or regular types, light, semi-bold, bold, black font-weights, underlined, and capitalised letters play an important role in literary texts. By distinguishing some units, parts of a sentence, and sometimes whole sentences, the author puts additional meanings into the context, as exemplified in the following excerpts. In Mafi's Shatter Me, the people enter Juliette's cell and the order is heard: "HANDS UP, FEET APART, MOUTHS SHUT. DON'T MOVE AND WE WON'T SHOOT YOU” (ch. 7). It is significant that the author does not use the exclamation mark but capital letters which attract the reader's attention. They create an atmosphere of anxiety and fear for Juliette. Short simple sentences in the imperative mood have 
parallel forms, express a complete thought (Kroeger, 2005, p. 52) and emphasise the direction of motivation in favour of the speaker.

The following example includes two highlighted words one of which is used to convey the despair of Vladimir Brik in Hemon's The Lazarus Project, and the other leads to a humorous effect: "A bolt of pain went through my intestines before I realized that it was not SADNESS but SARDINES" (ch. 6). The author uses paronomasia to exploits similar-sounding words for an intended comic effect. It has been established that humour and despair often come together in fiction. Humour is a vast field of human expression, and is used not just to entertain and that the humour that appears here is just a different mode of the reader's engagement.

The reader's emotional response to textual reality is always associated with personal experience. Actions endangering health or life are always decoded by readers as emotionally significant. In Lewycka's A Short History of Tractors in Ukrainian, the character teaches the girl to drive a car and the author uses capital letters to convey anxiety: "Back now, Valenka. Gently! Gently! STOP!" (ch. 30). Reduplicated elements intensified by exclamation marks lead to the effect of a slow increase in anxiety, and capitalised letters with the exclamation mark convey fear.

It is noteworthy that the central character Nikolai with real Ukrainian emotionalism realises the great power of the native language and its role in the triad language-thought-reality (Weretiuk, 2016, pp. 159-160), or evocative power of the language (Kral, 2009, p. 142). This can be traced in Nikolai's words addressed to his daughter: “...language is supremely important. In language are encapsulated not only thoughts but cultural values...” (ch. 13). Language expresses the idea of transcultural identity (Manolachi, 2014, p. 257), and transnational consciousness.

The problem of processing and modifying information in the human mind is important for modern linguistic and cognitive research (Friederici et al., 2017; Carreiras, 2010) since it allows for identifying different patterns of speech memory working that helps produce emotional knowledge. High emotional intensity is beneficial for the positively and negatively valenced texts. One of the major events with the powerful emotive effect is death and everything that goes with it. Stereotypically, people think of death as the end of their existence, often in the metaphysical dimension (Bezrukov, 2020, p. 376), that cannot but cause negative emotions. In Rushdie's The Golden House, the author describes the character's experience of emotion after his parents' death when he found himself alone with his problems, and finally decided to allow events to develop as they should: "It was too big for me, its value was high, the maintenance expenses and property taxes and so on would be difficult for me to come up with, and ET CETERA I DIDN'T CARE" (ch. 16). The full form of a Latin et cetera, which is usually abbreviated to etc., attracts attention that along with capital letters visualises despair and helplessness, creating an empathic effect.

Metaphorically, life and death are presented in the novels as the opposition of paradise and hell. In King's The Institute, we read: "Gladys escorted him... past the poster Kalisha had been sitting under, past the one reading JUST ANOTHER DAY IN PARADISE...” (ch. 4.18). Paradise is a contronym that evokes a contradictory, reverse meaning. The place where the kidnapped children find themselves in The Institute is a real hell for them. Such meaning replacing is a feature of fictional discourse. This is used for emotional colouring the information with a projection into the reader's emotional stress while producing knowledge of textual reality.

Death anxiety is one of the most emotionally significant, so all lexical units associated with the cessation of existence or burial rites evoke the reader's subconscious emotions. The examples of the feeling's intensity are found in Hemon's novel: "THE CEMETERY WAS behind a nondescript, crumbling wall...” (ch. 18); "THE CASKET LID is pried open...” (ch. 21). The author capitalises words 
to denote funeral objects, inducing the addressee's emotions because the reader takes in the cultural information throughout his/her life and responds to it accordingly and sometimes stereotypically.

Sometimes writers use italics for emphasis to engage the reader's emotional knowledge which includes knowledge of languages. For instance, Hemon transliterates the Ukrainian phrase goodnight: "Dobra nych, I said" (ch. 6), Lewycka uses a Ukrainian word denoting a type of rural locality: "They moved back to the khutor and tried to scratch a living" (ch.6); Rushdie transliterates the Indian clothing: "The dhobi. Here's the dirty laundry, dhobi" (ch. 35); and King reveals the meaning of a Ukrainian word in the dialogue between the characters: “'The vig,' Luke said. 'That's what my dad calls it. Short for vigorish. From the Ukrainian word for profits or winnings"' (ch. 2.9). Emotiogenic graphical means visualise different approaches to national identity and apperception through the lens of experience.

The text components become visually accentuated due to the combination of different graphical forms that is focused on even more attracting the reader's attention and helps the author to emphasise the main idea, as exemplified in King's novel: italic + capital letters = "Help me, I WANT TO GO HOME!" (ch. 2.4); capital letters + bold = "The MISSING SON, of course" (ch. 3.28).

The author creating textual reality puts emotional contagion that is common in daily life and transfers emotions from a sender to observers (Schoenewolf, 1990); he/she affects communicative space which includes the author and consumers of his literary texts. Thus, "the receivers' mood state is influenced by that of the sender" (Kuang et al., 2019, p. 2).

\section{4. "Emotiogenic" Punctuation: Highlighting Textual Reality}

The font immediately catches the reader's eye, but punctuation requires more detailed study and analysis as well as the perception of the authors' accents that provide insight into a text. The aforementioned have spurred us to create the section that touches upon the use or elimination of punctuation marks. They can be attributed to the main emotiogenic textual components since these signs highlight the information and influence the understanding of a literary text, affect the mode of interpreting it.

The emotionality of a text is considered the dual entity of expression and content through which the emotional connection in a relationship of addressers and addressees is manifested. Punctuation marks that activate the reader's emotional reactions to specific textual elements include exclamation and question marks, periods of ellipsis, dashes. Authors use periods of ellipsis to influence the reader's emotional perception: hesitation in Mafi's novel - "Yes. He makes me very... uncomfortable" (ch. 21); uncertainty in Lewycka's "But... are you sure...?" (ch. 27); evasion in Ishiguro's "Tommy, think back carefully. You said she got angry..." (ch. 3); thought process in Rushdie's "I am a very foolish fond old man... And to deal plainly, I fear I am not in my perfect mind" (ch. 33).

Exclamation marks according to conveyed emotions and used words with various evaluative components feel differently: the emotion of anger with dysphemism - "Psycho!" (Mafi, ch. 22); disgust with dysphemism to enhance expression's emotionality - "No! No! You cholera-sick eatbebby witch! You put no hand on me!" (Lewycka, ch. 25); despair and helplessness with appealing to God in the exclamation form - "His soul will wander for eternity. My God!" (Hemon, ch. 17); the emotion of admiration/surprise - "She was never like that!" (Ishiguro, ch. 4). 
Question marks can emphasise different emotional states: a rhetorical question containing an experience of emotion - "My promises aren't worth much, love," he whispers. "Or have you forgotten?" (Mafi, ch. 21); neglect with dysphemism - "Can't you see what a stupid little thing she is?" (Lewycka, ch. 26); persuasion of the reader with hypophora - "Of course not ashamed, why would one be ashamed? To own one's body, to care for it and make it excellent, to see no disgrace in beauty, that is liberation" (Rushdie, ch. 15); a rhetorical question with an expression of anger or disapproval of another person's actions - "Why did the government want Rambo out?" (Hemon, ch. 14).

Dashes attract the reader's attention and emphasise specified information and its emotive meaning: "There was a look about that slim, swarthy young man - clearly a Sicilian or a Jew - that could send a shiver of distrust into any honest man's heart" (Hemon, ch. 14); "How the fuck did I get here, to southwestern Ukraine, to the land of the pissed and passive, so far from everything anything - I loved? (ch. 14); "And since they were dead - slain - who would the most likely suspect be?" (King, ch. 3.28). It also seems interesting that the authors often use dashes to accentuate the readers' attention to the information in italic between dashes.

Sometimes the writers eliminate punctuation to influence the addressee's emotional perception, especially with repetition. In Rushdie's The Golden House, there is the SONG which consists of only one interjection $\mathrm{Oh}$ repeated 30 times (ch. 14) and sounds like recitative or howl. Other authors tend to use such a perception giving various intensifiers to the information. For example, in The Lazarus Project, Hemon uses the charactonym Lazarus 33 times (ch. 21) to describe the woman's longing for her brother Lazarus and to intensify the readers' emotion. Epizeuxis without punctuation marks creates an obsessive external sound. In Shatter Me, Mafi uses epizeuxis to convey the emotion of fear: "Five Five Five Five Five heartbeats" (ch. 20). The focus point is a symbolism embedded in the sentence: five heartbeats create parallelism.

It is paid special attention to the bright examples of using punctuation marks. Rushdie uses inversion of question marks to emotionalise given information and attract attention: "I wrote in my notebook, and beside it, in the margin, '??? or - NO."; "And as for the magic baby: instead of my earlier '??? or - NO,' ...the answer turned out to be YES” (ch. 6). Punctuation marks, conjunction or, and capital letters show hesitation according to the character's choice. In Mafi, the special readers' attention is attracted by repetition with gradation in an emotional speech to illustrate the emotion of insecurity and influence the readers' feelings: “'I' - I swallow - 'I am not - I'm not I'm -"' (ch. 21).

We assume that the emotional profile of a literary text becomes an emotionally significant structure due to the fact that the difference between the highlighted and background parts of a text influences the perceptual distinction of background and rhetorical figure. Using punctuation marks affects the creation of micro-communicative space between the author and reader, and using punctuation marks with different stylistic devices adds emotions. We conclude that stylistic devices in a literary text build up a consistent, linear explication of emotional knowledge of language and in language, about the world, and textual reality.

\section{Semantic-Stylistic Indicators as Predictors of the Readers' Emotionality}

In the article, stylistic devices are considered the predictors of particular emotions and serve as semantic indicators of the readers' emotional reactions to a text and its structural-semantic layer. 
To analyse a literary text with relation to the addressee's emotional knowledge, it is necessary to consider three components of emotionality: subjectivity shows emotional knowledge in a literary work; involvement points out the authors' emotional intentions; suggestibility indicates the readers' expected emotional reactions to textual reality. Emotionality in a literary text is actualised through a set of textual components that directly or indirectly indicate the nature of the author's emotional intentions - intra-narrative phenomena (Alders, 2015). It is represented in a text explicitly or implicitly, influencing the readers' emotional reactions to textual reality and objectifying the knowledge of the world to become emotional. The cognitive basis for the identification of the text's emotionally significant elements is readers' knowledge of emotion-based words and their ability to recognise stylistic devices.

Manifestations of semantic indicators of emotionality are associated with the implementation of textual ambiguity which stimulates the readers' emotional reactions. So, Mafi's Shatter Me starts: "I've been locked up for 264 days" (ch. 1) which is a flashback to provoke the readers' interest. The number of days is an indicator of emotionality.

The author's emotional intentions are embodied by the means of situational description which promotes the creation of attractive or unattractive images to influence the readers' emotions. In The Lazarus Project, Hemon describes the place where the main character walks: "The trees here are watered by our blood, Isador would say, the streets paved with our bones; they eat our children for breakfast, then dump the leftovers in the garbage" (ch. 1). The author uses hyperbole with soliloquy. The description of an area is aimed at forming the reader's expected negative attitude to a mentioned place. At the same time, it is a kind of hint to direct the interpretation of the whole novel. The uncomfortable and foreign city and the Jewish immigrant's place of murder are paralleled in the text.

To show the way linguistic means influence the readers' emotions, we consider Rushdie's The Golden House. At the beginning of the second chapter, communicative space takes the form of rhetorical parallel questions combined with hypophora: "What is a good life? What is its opposite? These are questions to which no two men will give the same answers" (ch. 2). There is a subconscious philosophical dialogue between the writer and reader which always receives an emotional response from the addressee.

Among the stylistic devices, the authors often use repetitions with other linguistic means, as in Ishiguro's Never Let Me Go: "Then Ruth said: 'He doesn't suspect a thing. Look at him. He really doesn't suspect a thing”" (ch. 1). To add emotion to the message, the author uses the adverb really. In King's The Institute, repetition with reduplication creates an emotional effect on readers to prompt them to certain actions: "They chanted at the end of the movies, and they chanted now. Think of the sparkler. Think of the sparkler. Think of the sparkler" (ch. 7.19). The analysed example as well shows that contemporary science fiction writers find "new ways of conveying unknown worlds" (Slusser \& Chatelain, 2002, p. 161).

The highest level of the emotional impact is achieved through multiple-used repetition of a word or sentence. In Mafi's novel, the sentence "I am not insane" (ch. 4) is used 8o times (!) that influences readers much. The imprisoned girl tries to convince herself that she is not crazy repeating the only sentence that provokes readers to empathy. All given examples prove that repetitions cannot be considered a formal redundancy since they add emotional colouring to speech.

The evaluative vocabulary with dysphemism and antiphrasis like any words of a lower range always arises due to the readers' emotional reactions. It is aimed at the addressees' emotional 
response and is easily seen in Ishiguro's novel: "But the next second Ruth gave a little laugh and said: “The idiot!" (ch. 1). In Rushdie's The Golden House, Nero asks McNally using dysphemism with hypophora to increase the intensity of the addressees' negative emotions: "Don't you know who I am, you asshole? I have built cities. I have conquered kingdoms. I am one of the rulers of the world" (ch. 35). The author uses anaphora in order to give emphasis to the pronoun $I$.

The obscene vocabulary "pronounced" by children and adults is the most emotional one, as shown in King's The Institute: "That's us, a bunch of Indians naïve enough to believe anything that sounds good, that sounds like a happy... fucking... ENDING!" (ch. 3.2). The writer uses allusion to point to the tragic events that took place in America and led to the near-extermination of Native Americans. The semantic ambiguity of the adjective naïve provokes the reader's interest and appears to be an indicator of emotionality enhanced by the obscene word, periods of ellipsis, and an exclamation mark after the capitalised word. Interpretation of this sentence allows readers to identify its emotional meaning in a text which is focused on evoking the readers' expected emotions. The American stereotypical happy end is contextually perceived as a contronym where the phrase gets a negative sense and causes the emotion of fear.

The emotionality in a literary text is actualised through a set of different stylistic devices. One of them is a sentence fragment to enhance a specific rhythm. "Shaking. With rage. I could see her. She was furious. But furious deep inside" (ch.3). Ishiguro uses a sentence fragment as an indicator of highlighting, expanding, and clarifying important information. The negative adjectives rage and furious create a predictable readers' negative attitude to a described character.

In Never Let Me Go, the writer uses an abrasive science fiction narrative to encourage readers to contemplate the essence and purpose of human life (Šemelák, 2018, p. 8), the true meanings of life and death (Huang, 2017, p. 1145). The debates regarding the empathetic effects of literature on readers are central to Never Let Me Go (Whitehead, 2011, p. 56). The highly sensitive topics described in the novel - inevitability of death and absurdity of human existence - actualise philosophical categories of the being and finitude of being, causing the emotional impact on the reader.

Charactonyms also help readers interpret textual reality. To illustrate this statement, there are some examples from the novels. Tim, the character of King's The Institute, compares himself with Count Dracula: “Then get some rest. You're about to become a creature of the night.' Like Count Dracula, Tim thought" (ch. 1.8). Count Dracula is a negative character, but readers perceive such information positively because it says about a night shift. In the novel, Kalisha compares one girl with Agent Mulder: "She's like Agent Mulder on that X-Files show. She wants to believe" (ch. 1.9). As Fox William Mulder is one of the positive protagonists of The $X$-Files television series, readers have positive emotions towards the character. In The Lazarus Project, the main character Lazarus is perceived by the inhabitants as a biblical anthroponym, so it is not surprising that, after his death, a demented woman addresses his sister: "Your brother will rise. ...Lazarus shall rise. Our Lord will be with us" (ch. 10). Perhaps these words influence readers who subconsciously begin to believe in the possibility of the character's resurrection.

The cognitive basis for the identification of charactonyms is objectified knowledge of addressees about a famous person. As Jeshion (2009) emphasises, "proper names and mental names possess an important function that outstrips their semantic and psycho-semantic functions as common, rigid devices of direct reference and singular mental representations of their referents, respectively" (p. 370). 
The variety of semantic-stylistic means makes it possible to show the heterogeneity of textual semantics a certain part of which may become accentuated, especially when it is associated with the explication of emotional knowledge, i.e. it becomes emotionally significant. The semantics of a literary text as a whole becomes a conceptual basis for highlighting the emotional profile of a text. A literary text can be considered the author's and reader's communicative space that is a special form of organization of the conceptual worldview. The authors use their works to influence the readers' system of values, knowledge, stereotypes, worldviews, hopes, and desires. Since the meanings of a literary text are inextricably linked with emotional and evaluative categories that form the author's and reader's attitude to the inner and outer world, the emotiogenic means of creating communicative space appear to be significant elements that ultimately affect textual reality.

\section{Conclusion}

Emotionality of a literary text can be enhanced when the reader becomes emotionally transported by fictional narratives through the emotiogenic means. It is manifested in fiction through a set of indicators as organised textual components and associated with the explication of emotions in a literary text. The traditional emotional indicators, in particular emotional vocabulary, have received comprehensive coverage in modern linguistics, but other means of the emotional impact on the perception of a text are still out of detailed studying.

The authors of the article have drawn attention to another perspective of research on the emotionally significant textual components, proposing their own classification of the emotiogenic means of representing emotions in the artistic dimension. This has allowed for distinguishing the following types of the emotiogenic means: graphical and visual, punctuation, and semantic-stylistic ones. Such an approach has provided insight into the writers' strategies of using these means for creating communicative space. The proposed classification of indicators of text emotionality enables to clearly distinguish the stages of the semantic and emotional perception of literature and complements the theoretical and empirical basis of the text-centric approach in humanities.

The article combines linguo-stylistic, cultural, and psychological insights through the study of English-language fictional discourse in order to highlight an interdisciplinary approach to postmodern literature. The novels by Salman Rushdie, Tahereh Mafi, Marina Lewycka, Kazuo Ishiguro, Alexandar Hemon, and Stephen King have been analysed to explicate the strategies of using the emotiogenic means for creating and transforming communicative space and textual reality.

Emotional areas of textual semantics stand out from emotionally neutral areas and affect a literary text, forming an emotionally significant structure of fictional narratives. The components of a text become emotionally significant and can be considered emotional signs in textual space to stimulate the readers' emotional reactions. Their perception is based on communication parties' knowledge. Depending on whether the semantics of textual elements are emotionally significant or become so due to non-traditional graphical and visual images, use or elimination of punctuation marks, and linguistic units, including an evaluative component, emotional modality, and semantics, occasional and usual elements can be identified. The emotiogenic usual components are embedded in their semantics while the occasional elements become emotionally significant due to their visual emphasis and punctuation in a text.

This study contributes to the field of investigation of the emotiogenic means in fictional narrative experience that provides an answer to the question of whether the interpretation of these 
means serves as a probable emotional trigger of the text's impact on the reader. The confines of the emotiogenic means are determined by the framework of the emotional situation reflected in a literary text. This situation influences decoding the textual code and affects the interpretation of the emotional and evaluative meaning. The usage of the emotiogenic means in the selected novels, written by the authors of different ethnic affiliations, is determined by the writers' multicultural experience that correlates with creativity.

An interesting avenue for further research is to conduct an experiment among readers that includes distinguishing the emotional indicators for the following criteria: deviations from the language norms, iconicity, and textual symbols. Another area for future research is an interdisciplinary reflection on emotionality in the semantic and cognitive aspect, where the content of the entire text, depending on the author's intentions, can be described not only through various language forms associated with methods of structuring emotional knowledge but also from a different perspective of the author's vision of the world, which involves the cognitive and semantic aspects.

\section{References}

Alders, M. (2015). Introduction: Social minds in factual and fictional narration. Narrative, 23, 113-122. https://doi.org/10.1353/nar.2015.0009

Aytug, Z. G., Rua, T., Brazeal, D. V., Almaraz, J. A., \& González, C. B. (2018). A socio-cultural approach to multicultural experience: Why interactions matter for creative thinking but exposures don't. International Journal of Intercultural Relations, 64, 29-42. https://doi.org/10.1016/j.ijintrel.2018.03.004

Bal, P. M., Butterman, O. S., \& Bakker, A. B. (2011). The influence of fictional narrative experience on work outcomes: A conceptual analysis and research model. Review of General Psychology, 15(4), 361-370. https://doi.org/10.1037/aoo25416

Bezrukov, A. (2020). Transformation and interpretation of gender concepts in metaphysical dimension: From contemplative worldview to transpersonal experience. Humanities $\mathcal{E}$ Social Sciences Reviews, 8(4), 373-381. https://doi.org/10.18510/hssr.2020.8437

Brock, T. C., Strange, J. J., \& Green, M. C. (2002). Power beyond reckoning. In In M. C. Green, J. J. Strange \& T. C. Brock (Eds.), Narrative impact: Social and cognitive foundations (pp. 1-15). Lawrence Erlbaum.

Bruner, J. S. (2009). Actual minds, possible worlds. Harvard University Press.

Carbaugh, D. (2007). Cultural discourse analysis: Communication practices and intercultural encounters. Journal of Intercultural Communication Research, 36(3), 167-182. https://doi.org/10.1080/1747575070173709o

Carreiras, M. (2010). Language across the mind and brain. Frontiers in Psychology, 1, 14. https://doi.org/10.3389/fpsyg.2010.00014

Cheng, C.-Y., Leung, A. K., \& Wu, T.-Y. (2011). Going beyond the multicultural experience-creativity link: The mediating role of emotions. Journal of Social Issues, 67(4), 806-824. https://doi.org/10.1111/j.1540-4560.2011.01729.x

Cyzman, M. (2015). "Is there a problem about fictional discourse"? J. Searle vs. R. Rorty. Ruch Filozoficzny, 71(4), 63-76. https://doi.org/10.12775/rf.2015.004 
Danes, F. (2004). Universality vs. culture-specificity of emotion. In E. Weigand (Ed.), Emotion in dialogic interaction (pp. 23-32). John Benjamins Pub. https://doi.org/10.1075/cilt.248.04dan

Friederici, A. D., Chomsky, N., Berwick, R. C., Moro A., \& Bolhuis, J. J. (2017). Language, mind and brain. Nature Human Behaviour, 1, 713-722. https://doi.org/10.1038/s41562-017-0184-4

Gerrig, R. J. (1994). Narrative thought? Personality and Social Psychology Bulletin, 20(6), 712-715. https://doi.org/10.1177/0146167294206009

Glynn, D. (2014). The social nature of ANGER: Multivariate corpus evidence for context effects upon conceptual structure. In I. Novakova, P. Blumenthal, D. Siepmann (Eds.), Emotions and discourse (pp. 69-82). Peter Lang.

Goldstein, T. R. (2009). The pleasure of unadulterated sadness: Experiencing sorrow in fiction, nonfiction, and "in person." Psychology of Aesthetics, Creativity, and the Arts, 3(4), 232-237. https://doi.org/10.1037/aoo15343

Harker, W. J. (1988). Literary communication: The author, the reader, the text. Journal of Aesthetic Education, 22(2), 5-14. https://doi.org/10.2307/3333119

Hatavara, M., Hyvärinen, M., Mäkelä, M., \& Mäyrä, F. (2018). Narrative theory, literature, and new media: Narrative minds and virtual worlds (Routledge Interdisciplinary Perspectives on Literature). Routledge.

Hyatt, J., \& Simons, H. (1999). Cultural codes - Who polds the key? Evaluation, 5(1), 23-41. https://doi.org/10.1177/13563899922208805

Hemon, A. (2008). The Lazarus Project. Riverhead Books.

Hofstede, G., Hofstede, G. J., \& Minkov, M. (2010). Cultures and organizations: Software of the mind ( $3^{\text {rd }}$ ed.). McGraw-Hill Education.

Huang, Yu-min. (2017). Life in Kazuo Ishiguro's Never Let Me Go. Journal of Literature and Art Studies, 7(9), 1145-1157. https://doi.org/10.17265/2159-5836/2017.09.006

Ingarden, R., Crowley, R. A., \& Olsen, K. (1980). Cognition of the literary work of art (Studies in phenomenology and existential philosophy). Northwestern University Press.

Ishiguro, K. (2005). Never Let Me Go. Knopf Doubleday Publishing Group.

Jeshion, R. (2009). The significance of names. Mind E Language, 24(4), 370-403. https://doi.org/10.1111/j.1468-0017.2009.01367.x

King, S. (2019). The Institute. Scribner.

Kneepkens, E. W. E. M., \& Zwaan, R. A. (1995). Emotions and literary text comprehension. Poetics, 23(1-2), 125-138. https://doi.org/10.1016/0304-422x(94)00021-w

Kövecses, Z. (2014). Metaphor and emotion: Language, culture, and body in human feeling. Studies in emotion and social interaction second series. Cambridge University Press.

Kral, F. (2009). Critical identities in contemporary Anglophone diasporic literature. Palgrave Macmillan. https://doi.org/10.1057/9780230244429

Kroeger, P. R. (2005). Analyzing English grammar. Cambridge University Press. 
Kuang, B., Peng, S., Xie, X., \& Hu, P. (2019). Universality vs. cultural specificity in the relations among emotional contagion, emotion regulation, and mood state: An emotion process perspective. Frontiers in Psychology, 10, 186. https://doi.org/10.3389/fpsyg.2019.00186

Leung, A. K., \& Chiu, C. (2010). Multicultural experience, idea receptiveness, and creativity. Journal of CrossCultural Psychology, 41(5-6), 723-741. https://doi.org/10.1177/0022022110361707

Lewycka, M. (2005). A Short History of Tractors in Ukrainian. Viking Press.

Maass, D. (2016). The emotional craft of fiction: How to write the story beneath the surface. Writer's Digest Books.

Mar, R. A., Oatley, K., Djikic, M., \& Mullin, J. (2011). Emotion and narrative fiction: Interactive influences before, during, and after reading. Cognition E Emotion, 25(5), 818-833. https://doi.org/10.1080/02699931.2010.515151

Mafi, T. (2011). Shatter Me. HarperCollins.

Manolachi, M. (2014). Cultural tractors and gender roles in "A Short History of Tractors in Ukrainian" by Marina Lewycka. In M. D. Alexandru, M. Nicolaescu \& H. Smith (Eds.), Between history and personal narrative: East European women's stories of migration in the new millennium (pp. 249-264). LIT Verlag.

Meskin, A. (2003). Emotions, fiction, and cognitive architecture. The British Journal of Aesthetics, 43(1), 1834. https://doi.org/10.1093/bjaesthetics/43.1.18

Miall, D. S., \& Kuiken, D. (2002). A feeling for fiction: Becoming what we behold. Poetics, 30(4), 221-241. https://doi.org/10.1016/s0304-422x(02)ooo11-6

Oatley, K. (1999). Why fiction may be twice as true as fact: Fiction as cognitive and emotional simulation. Review of General Psychology, 3(2), 101-117. https://doi.org/10.1037/1089-268o.3.2.101

Oatley, K. (2002). Emotions and the story world of fiction. In M. C. Green, J. J. Strange \& T. C. Brock (Eds.), Narrative impact: Social and cognitive foundations (pp. 39-70). Lawrence Erlbaum.

Oster, U. (2010). Angst and fear in contrast: A corpus-based analysis of emotion concepts. In M. Brda, I. Raffaelli \& M. Ž. Fuchs (Eds.), Cognitive linguistics between universality and variation (pp. 327355). Cambridge Scholars Press.

Palmer, A. (2004). Fictional minds. University of Nebraska Press.

Palmer, A. (2010). Social minds in the novel. Ohio State University Press.

Phillips, J. (2000). Two theories of fictional discourse. American Philosophical Quarterly, 37(2), 107-119.

Predelli, S. (2020). Fictional discourse: A radical fictionalist semantics. Oxford University Press. https://doi.org/10.1093/oso/9780198854128.001.0001

Rushdie, S. (2017). The Golden House. Jonathan Cape.

Schoenewolf, G. (1990). Emotional contagion: Behavioral induction in individuals and groups. Modern Psychoanalysis, 15, 49-61.

Šemelák, M. (2018). The suffering of existence in Kazuo Ishiguro's Never Let Me Go. Ars Aeterna, 10(2), 8-17. https://doi.org/10.1515/aa-2018-0oo8 
Slusser, G., \& Chatelain, D. (2002). Conveying unknown worlds: Patterns of communication in science fiction. Science Fiction Studies, 29(2), 161-185.

Song, M. (2019). Aptness of fiction-directed emotions. The British Journal of Aesthetics, 6o(1), 45-59. https://doi.org/10.1093/aesthj/ayzo28

Stamou, A. G. (2018). Sociolinguistics of fiction. Discourse, Context \& Media, 23, 1-5. https://doi.org/10.1016/j.dcm.2018.03.003

Thomasson, A. L. (2003). Fictional characters and literary practices. The British Journal of Aesthetics, 43(2), 138-157. https://doi.org/10.1093/bjaesthetics/43.2.138

Weretiuk, O. (2016). Identifying the Ukrainian: Marina Lewycka's A Short History of Tractors in Ukrainian. Studia Anglica Resoviensia, 13, 154-164. https://doi.org/10.15584/sar.2016.13.15

Whitehead, A. (2011). Writing with care: Kazuo Ishiguro's Never Let Me Go. Contemporary Literature, 52(1), 54-83. https://doi.org/10.1353/cli.2011.0012

Zwaan, R. A. (2004). The immersed experiencer: Toward an embodied theory of language comprehension. In B. H. Ross (Ed.), The psychology of learning and motivation: Advances in research and theory, (vol. 44, pp. 35-62). Elsevier Science.

Dr. Andrii Bezrukov, Asst. Prof. at Philology and Translation Dept., Dnipro National University of Railway Transport, Ukraine. Research interests focus on interdisciplinary studies, Englishlanguage literature, comparative literature studies, postmodern metafiction, literary process review, and literary theory.

Dr. Oksana Bohovyk, Snr. Lecturer at Philology and Translation Dept., Dnipro National University of Railway Transport, Ukraine. Research interests focus on interdisciplinary studies, English and Ukrainian literature, discourse and dialogue, corpus linguistics, cognitive linguistics, linguistic and cultural relativity. 